\title{
EVALUATION OF PIPE BENDING REFERENCE STRESS EQUATIONS
}

\author{
M. Verstraete ${ }^{1}$, W. De Waele ${ }^{1}$, S. Hertelé ${ }^{1}$, R. Denys ${ }^{1}$ \\ ${ }^{1}$ Ghent University, Laboratory Soete, Belgium
}

\begin{abstract}
The use of a Failure Assessment Diagram (FAD) is widespread in the assessment of weld defects. To determine whether a defect is acceptable or not, this requires the calculation of a load ratio and a fracture ratio for the defect under consideration. Nowadays, many formulae are available to calculate these two quantities and no clear guidance is given on which equation(s) should (not) be used. A partial clarification of this problem is achieved by comparing different reference stress equations. This article is concerned with such comparison, for the specific case of welded pipes subjected to a bending load. A large set of historical experimental data has been investigated in which defected pipes were subjected to an increasing bending force until failure occurred. Two kinds of reference stress equations are considered, full pipes subjected to a bending load and flat plates subjected to a uniform tension load. From the equations under consideration, the flat plate solution of Goodall \& Webster and the empirical full pipe equations of Willoughby and Wilkowski \& Eiber describe the pipe failure in the most accurate way.
\end{abstract}

Keywords Failure Assessment Diagram, Reference stress, Pipe bending, Defects

\section{INTRODUCTION}

Girth welds of pipelines unavoidably contain defects. Whether these defects are acceptable or not is, in codes and standards, often determined by using a Failure Assessment Diagram (FAD) [1, 2]. This paper focuses on the assessment prescribed in the general European FITNET procedure [3].

Using a FAD, two values have to be calculated in order to determine the severity of a defect. The first value is the fracture ratio $\left(K_{r}\right)$, which is determined as the ratio of a stress intensity factor to the material's fracture toughness. The stress intensity factor can be calculated by different available formulae $[3,4]$. In this paper, only the Newman and Raju equation (see Appendix B) will be used. The second value is the load ratio $\left(L_{r}\right)$, determined as the ratio of a reference stress to the material's yield strength. The reference stress can be calculated according to many formulae, each of them applicable to a specified load condition and geometry. If the calculated failure assessment point $\left(L_{r}, K_{r}\right)$ is located underneath the failure assessment curve, the defect is considered to be acceptable (see Figure 1).

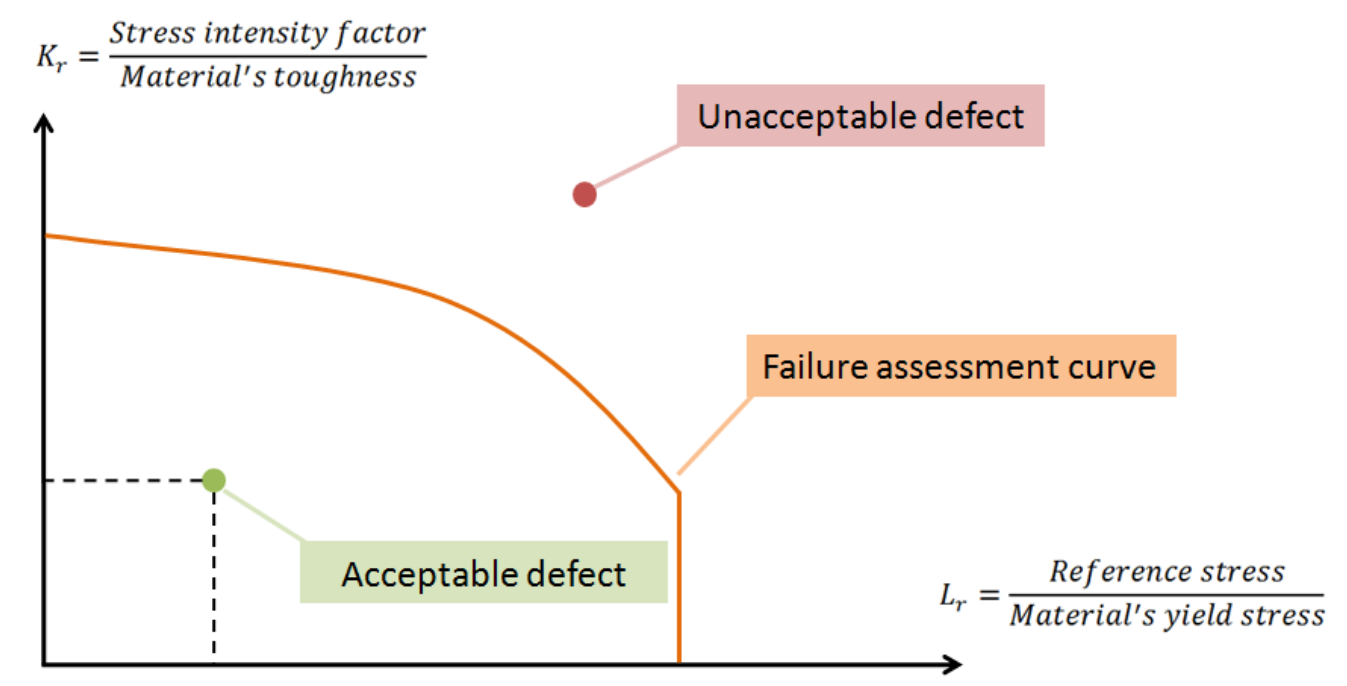

Figure 1. The Failure Assessment Diagram (FAD) can be used to determine the acceptability of a defect

In the open literature, many equations are available to calculate the reference stress, which makes it complicated to decide which equation should be used. Therefore a comparison of reference stress equations was made for pipes subjected to a bending moment, based on a large amount of full scale test data $[5,6]$. The equations under investigation were derived either for full pipes subjected to a bending load or for flat plates subjected to a uniform tension load. This paper briefly describes the used reference stress 
equations and then compares them based on the historical experimental data. Final conclusions provide advice on which equation should be used for the considered case.

\section{REFERENCE STRESS EQUATIONS}

Following a literature review, several reference stress equations have been selected. The following paragraphs give a brief description of these equations together with their limitations. The defect dimensions are defined according to Figure 2.
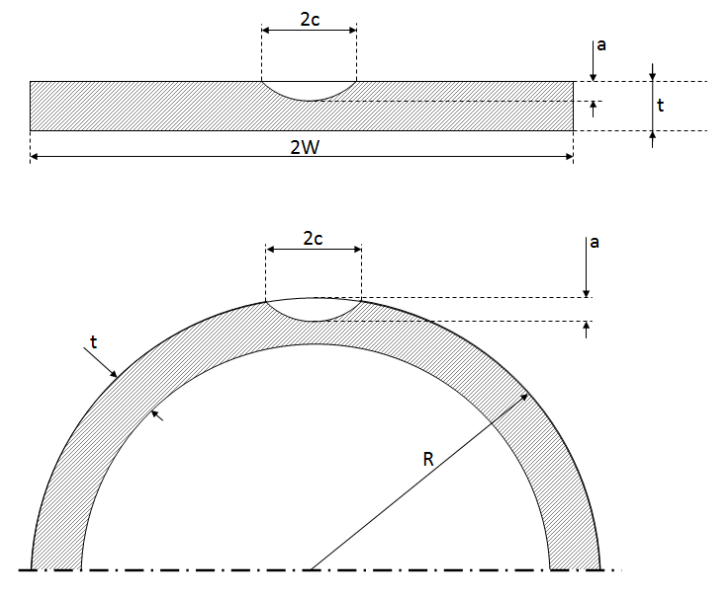

Figure 2. Pipe, plate and defect dimensions used in limit load equations

The pipes are loaded as illustrated in Figure 3. From the applied bending moment, the bending stress can be calculated in two ways, elastically $\left(\sigma_{b, e}\right)$ and plastically $\left(\sigma_{b, p}\right)$ :

$$
\begin{aligned}
& \sigma_{b, e}=\frac{M}{\pi \cdot R^{2} \cdot t} \\
& \sigma_{b, p}=\frac{M}{4 \cdot R^{2} \cdot t}
\end{aligned}
$$

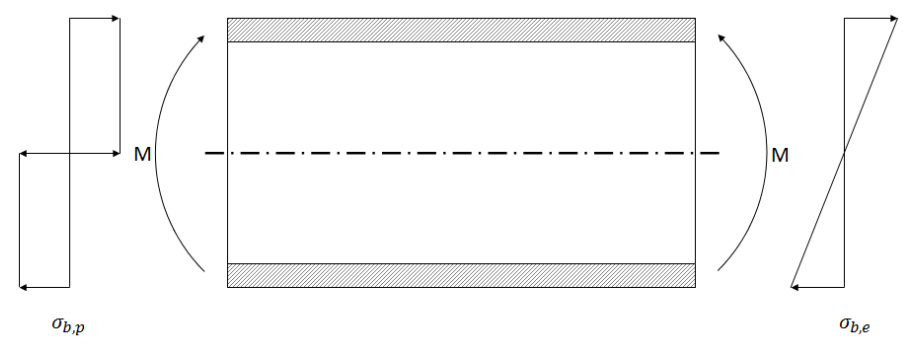

Figure 3. Applied load

The reference stress equations can be divided into two subgroups. On the one hand reference stress can be calculated using equations for entire pipes subjected to bending. On the other hand reference stress equations obtained from flat plates subjected to a uniform tensile stress are discussed. This second category makes sense since the pipe section containing the defect is in the tension loaded region of the pipe. Besides for large D/t-ratios this section is subjected to a (nearly) constant stress and the curvature of the plate is limited.

\section{1 $\quad$ Full pipe bending reference stress solutions}

The applied stress (elastically or plastically) used in these equations differs, depending on the way the equations were developed.

\subsubsection{Wilkowski and Eiber equation [7]}

The Wilkowski and Eiber equation is empirical. The reference stress $\left(\sigma_{r e f}\right)$ can be calculated using the following equations:

$$
\begin{aligned}
\frac{\sigma_{\mathrm{b}, \mathrm{e}}}{\sigma_{\text {ref }}} & =\frac{\eta}{1-\frac{(1-\eta)}{\mathrm{M}_{0}}} \\
\mathrm{M}_{0} & =\sqrt{1+0.26 \mathrm{z}+47 \mathrm{z}^{2}-59 \mathrm{z}^{3}}
\end{aligned}
$$


With:

$$
\begin{aligned}
& \eta=1-\mathrm{a} / \mathrm{t} \\
& z=\mathrm{c} / \pi \mathrm{R}
\end{aligned}
$$

The dimensionless parameter $\eta$ represents the size of the uncracked ligament $(t-a)$ relative to the wall thickness $(t)$, whilst the parameter $z$ represents the relative length of the crack $(2 c)$ to the circumference of the pipe $(2 \pi R)$. The Wilkowski and Eiber equation has been validated based on tests for $z$-values up to 0.15 .

\subsubsection{Willoughby equation [7]}

Another empirical equation is the Willoughby equation which has been experimentally validated for $\eta$ values up to 0.2 . The Willoughby reference stress is calculated using the next equation:

$$
\frac{\sigma_{\mathrm{b}, \mathrm{e}}}{\sigma_{\mathrm{ref}}}=1-1.6(1-\eta) \beta
$$

With:

$$
\beta=\mathrm{c} / \mathrm{R}
$$

The dimensionless parameter $\beta$ represents the semi-angle of the circumferential crack in a cylinder.

\subsubsection{Miller equation [7]}

This analytical equation was derived by Miller and is advised by the FITNET procedure. The net section collapse formula contains two different equations depending on the position of the neutral axis:

$$
\begin{array}{ll}
\frac{\sigma_{\mathrm{b}, \mathrm{p}}}{\sigma_{\mathrm{ref}}}=\cos \frac{(1-\eta) \beta}{2}-\frac{(1-\eta) \sin \beta}{2} & \text { if } \beta \leq \frac{\pi}{1+\eta} \\
\frac{\sigma_{\mathrm{b}, \mathrm{p}}}{\sigma_{\mathrm{ref}}}=\eta \sin \frac{\pi-\beta(1-\eta)}{2 \eta}+\frac{(1-\eta) \sin \beta}{2} & \text { if } \beta>\frac{\pi}{1+\eta}
\end{array}
$$

No limitations have been found for this equation.

\subsection{Plate tension reference stress solutions}

The applied stress used to calculate the reference stress, is the plastic bending stress $\left(\sigma_{b, p}\right)$ as defined in equation 2. From a comparison of different plate widths, it was seen that a plate-half width $(W)$ of $300 \mathrm{~mm}$ resulted in the most accurate predictions for the equations described below. Therefore plate half-width ( $W$ ) is assumed to be $300 \mathrm{~mm}$ except for these two cases which define the plate width. Firstly the FITNET plate equation, which prescribes a plate width equal to the sum of the crack length (2c) and two times the wall thickness $(2 t)$. Secondly, the net section yielding equation is based on a reference stress calculation using a fixed plate width of $300 \mathrm{~mm}$.

\subsubsection{Goodall \& Webster equation[8]}

An analytical reference stress equation for plates subjected to bending and tensile loading was presented by Goodall \& Webster. This equation is applicable to a/t-ratios below 0.5 . Reducing this equation to pure tension results in the following reference stress equation:

$$
\frac{\sigma_{r e f}}{\sigma_{b, p}}=\frac{\gamma+\left\{\gamma^{2}+\left[(1-\gamma)^{2}+2 \gamma(\alpha-\gamma)\right]\right\}^{1 / 2}}{(1-\gamma)^{2}+2 \gamma(\alpha-\gamma)}
$$

With:

$$
\begin{aligned}
\alpha & =a / t \\
\gamma & =(a c) /(W t)
\end{aligned}
$$




\subsubsection{Lei equation [9]}

The Lei equation is based on a large number of finite element simulations. The crack geometries used to derive the reference stress equation have $a / t$-ratios from 0.2 to 0.8 and $a / c$-ratios from 0.2 to 1.0 . The reference stress, in case of pure tension, can be calculated from the following equations:

$$
\begin{array}{ll}
\frac{\sigma_{b, p}}{\sigma_{r e f}}=\frac{d_{1}}{\gamma+\sqrt{\gamma^{2}+d_{1}}} & \psi \leq 1 \\
\frac{\sigma_{b, p}}{\sigma_{r e f}}=\frac{d_{2}}{\gamma \frac{1-\psi}{\psi-\gamma}+\sqrt{\left(\frac{1-\psi}{\psi-\gamma}\right)^{2}+\frac{\psi}{\psi-\gamma} d_{2}}} & \psi>1
\end{array}
$$

With:

$$
\begin{aligned}
d_{1} & =(1-\gamma)^{2}+2 \gamma(\psi-\gamma) \\
d_{2} & =(1-\gamma)\left[2-\psi \frac{1-\gamma}{\psi-\gamma}\right]+2 \gamma(\psi-\gamma) \\
\psi & =\frac{a}{t} \\
\beta_{p} & =\frac{c}{W} \\
\gamma & =\psi \beta_{p}
\end{aligned}
$$

\subsubsection{FITNET plate equation [3]}

The FITNET plate solution is based on the Lei equation, but prescribes the plate width to be used. The plate width $(2 \mathrm{~W})$ recommended by the FITNET standard is given by:

$$
2 W=2 c+2 t
$$

\subsubsection{Net section yielding equation [10,11]}

This reference stress equation is basically a flat plate solution, which has been extensively used for the analysis of wide plate test results (with $2 W=300 \mathrm{~mm}$ ). The reference stress can be calculated using the following equation:

$$
\frac{\sigma_{b, p}}{\sigma_{r e f}}=1-\frac{a c}{W t}
$$

When the defect under consideration has a length exceeding $300 \mathrm{~mm}$, the equation is assumed to be invalid.

\subsubsection{Sattari-Far equation [12]}

This equation has been determined by using finite-element analysis. The analysis was carried out on configurations containing defects with $\eta$-values ranging from 0.2 to 1.0 and $c / a$ ranging from 1 to 5 . The reference stress can be calculated solving the following equation:

With:

$$
\frac{\sigma_{\mathrm{b}, \mathrm{p}}}{\sigma_{\mathrm{ref}}}=(1-\zeta)^{0.87}
$$

$$
\zeta= \begin{cases}\frac{a c}{W t} & W<c+t \\ \frac{a \mathrm{c}}{t(c+t)} & W>c+t\end{cases}
$$




\section{EXPERIMENTAL TEST DATA}

The evaluation and comparison of the different equations is based on 59 full scale bend tests on (welded) pipes [5,6]. The $D / t$-ratio of the tested pipes ranges from 28 to 90 and $c / R$ is between 0.01 and 0.78 . A summary of these test data, including the material's yield strength $\left(\sigma_{Y S}\right)$, the bending moment at failure $\left(M_{\text {fail }}\right)$ and fracture toughness $\left(K_{\text {mat }}\right)$ is presented in appendix A.

\section{ASSESSMENT PROCEDURE}

The assessment of each defect requires the calculation of the specific load ratio $\left(L_{r}\right)$ and fracture ratio $\left(K_{r}\right)$ [13]. Because this paper focuses on the comparison of reference stress equations, $K_{r}$ is always calculated using the widely accepted plate solution derived by Newman and Raju (see Appendix B - [4]). This formula is also used in the BS7910 and the FITNET code [2,3]. The different reference stress equations discussed in section 2 are used to calculate $L_{r}$ for every pipe failure.

The failure assessment curve used for this comparison is the curve prescribed in the FITNET code in case of an Option 1 assessment. It should be stated that the FITNET Option 1 does not account for ductile tearing although this was reported for some failures. This can lead to a certain degree of over conservatism resulting from the fact that too much defects are assessed as unsafe. This might be prevented by using a higher assessment level, which unfortunately requires input data that is not available (p.e. the CTOD R-curve and the amount of tearing). Nevertheless, assuming a round-house post-yield behavior, the failure assessment curve for an Option 1 assessment is described by:

$$
\begin{array}{lc}
K_{r}=f\left(L_{r}\right)=\left(1+0.5 L_{r}^{2}\right)^{-1 / 2} \cdot\left[0.3+0.7 \cdot \exp \left(-\mu L_{r}^{6}\right)\right] & L_{r} \leq 1 \\
K_{r}=f\left(L_{r}\right)=f(1) L_{r}^{(N-1) /(2 N)} & 1<L_{r} \leq L_{r, \max }
\end{array}
$$

With:

$$
\begin{aligned}
& N=0.3\left(1-\sigma_{Y S} / \sigma_{U T S}\right)[-] \\
& L_{r, \max }=0.5\left(1+{ }^{\sigma_{U T S}} / \sigma_{Y S}\right)[-]
\end{aligned}
$$

Combining the calculated failure assessment curve and the failure assessment point $\left(L_{r}, K_{r}\right)$ enables a plot in the FAD. The FADs for all reference stress equations can be seen in Figure 4 and 5 . The assessment points located on the vertical axis represent invalid predictions because $\eta$ or $z$ was beyond the limitations discussed in section 2.1. For one case, the Newman and Raju equation could not be used because its limitations were exceeded. This assessment point is not presented in the FADs. 
Day of Research 2010 - February 10 - Labo Soete, Ghent University, Belgium

a)

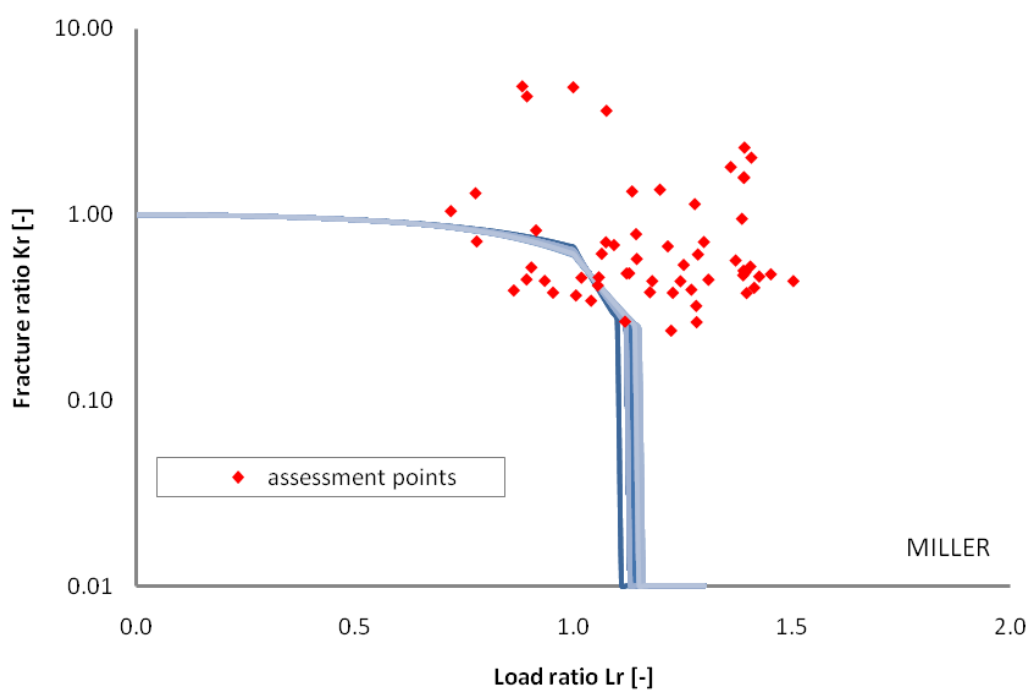

b)

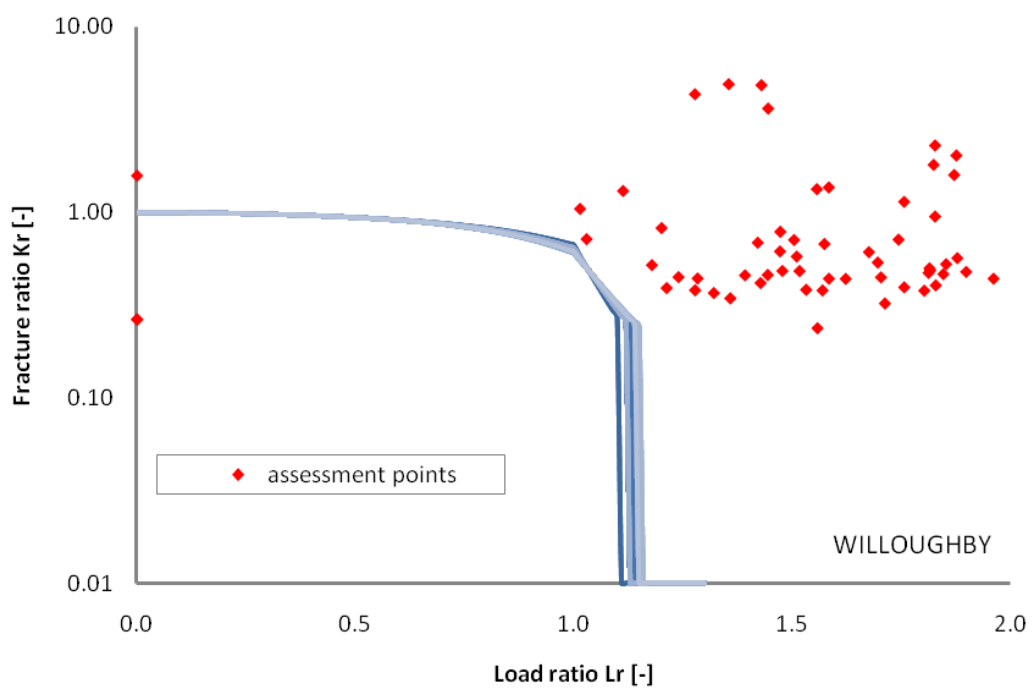

c)

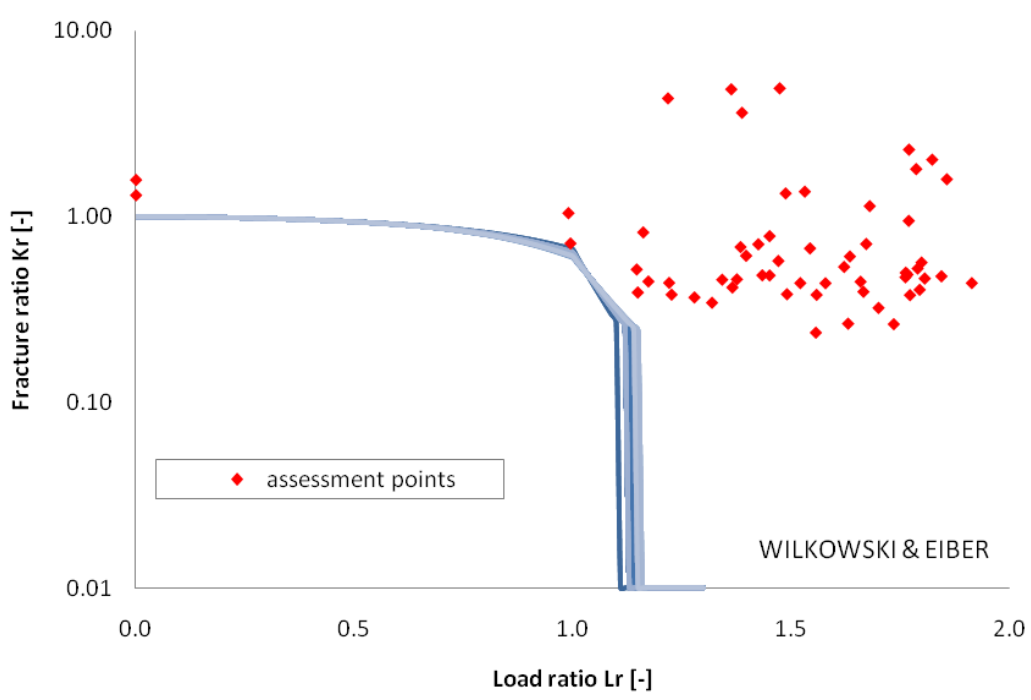

Figure 4. Failure assessment points using the Miller equation (a), the Willoughby equation (b) and the Wilkowski and Eiber equation (c). 
a)

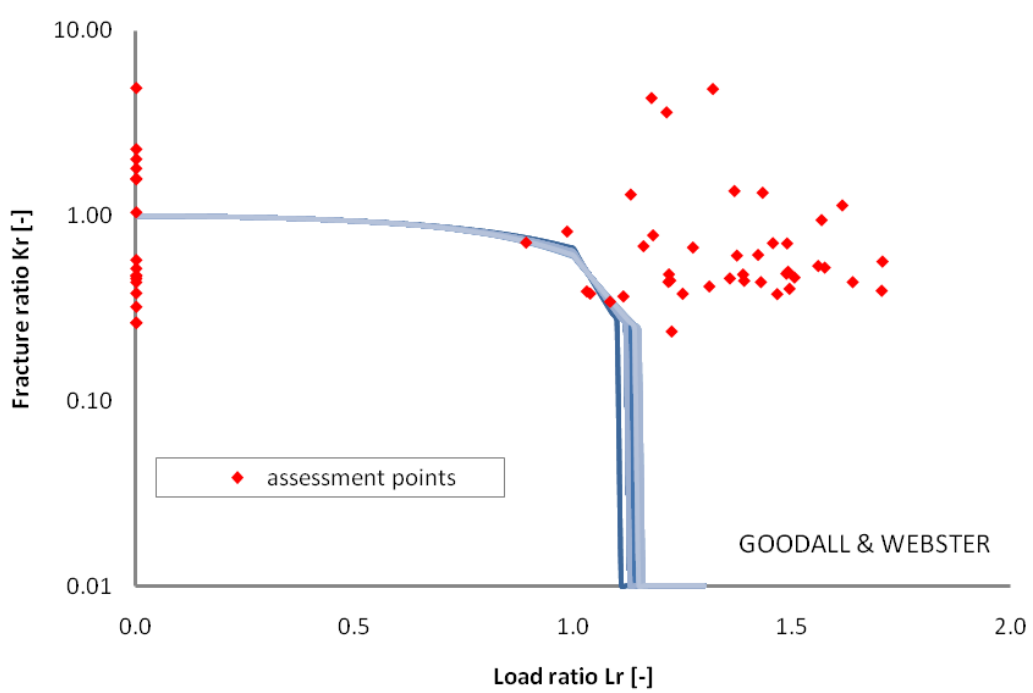

b)

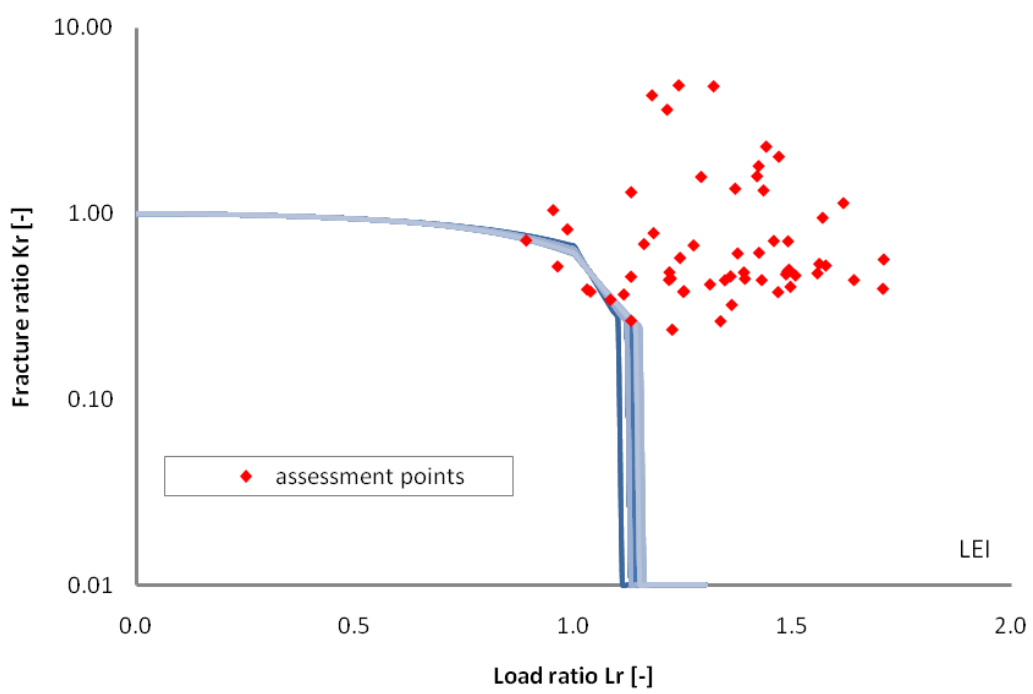

c)

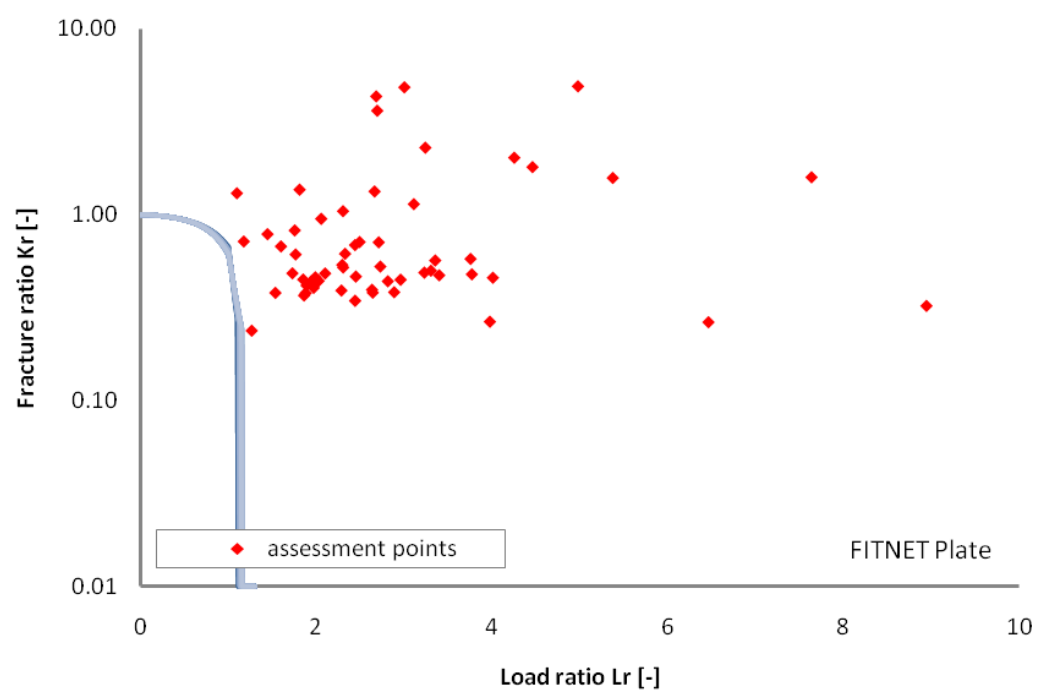

Figure 5. Failure assessment points using the Goodall \& Webster equation (a), the Lei equation (b) and the FITNET Plate equation (c). 
Day of Research 2010 - February 10 - Labo Soete, Ghent University, Belgium

d)

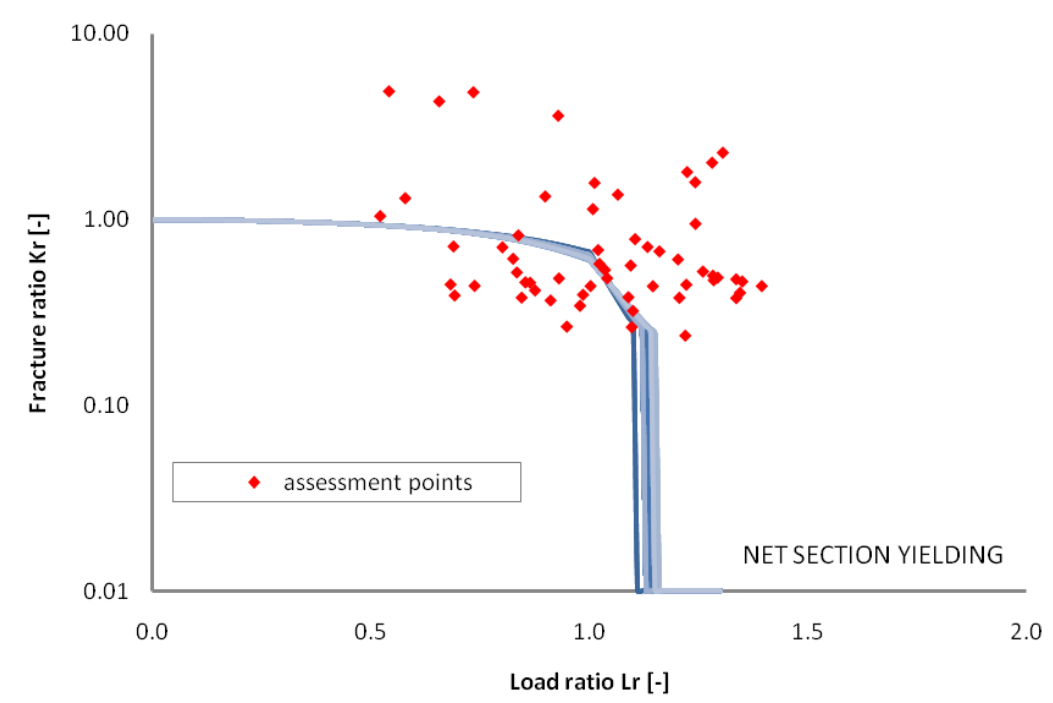

d)

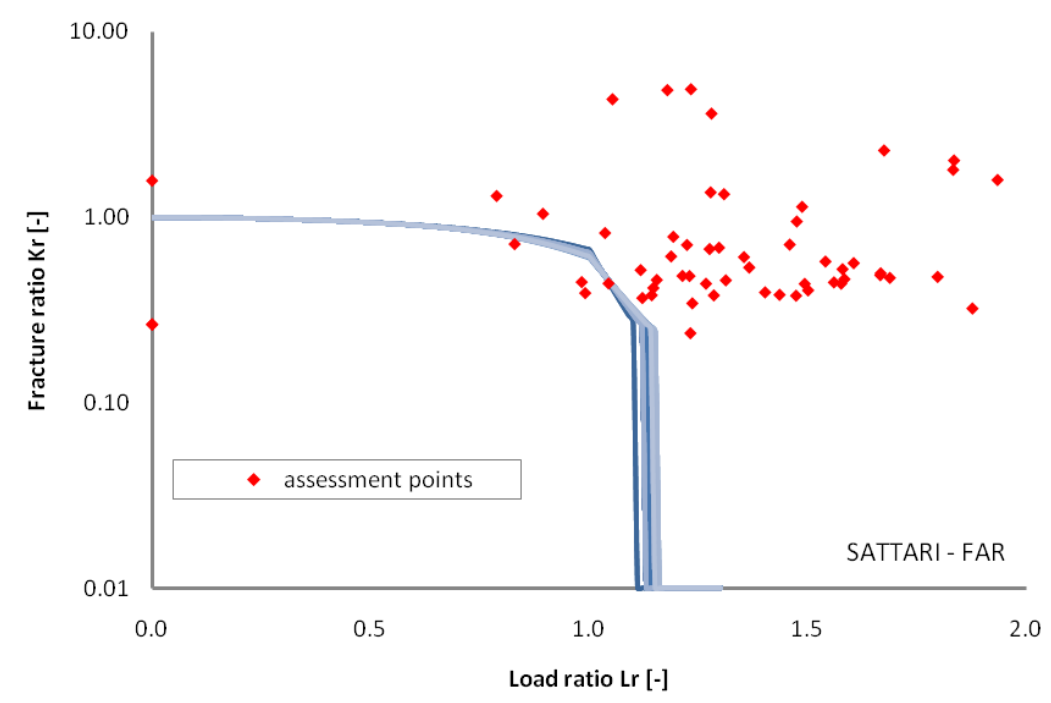

Figure 5. Failure assessment points using the Net Section Yielding equation (d) and the Sattari-Far equation (e).
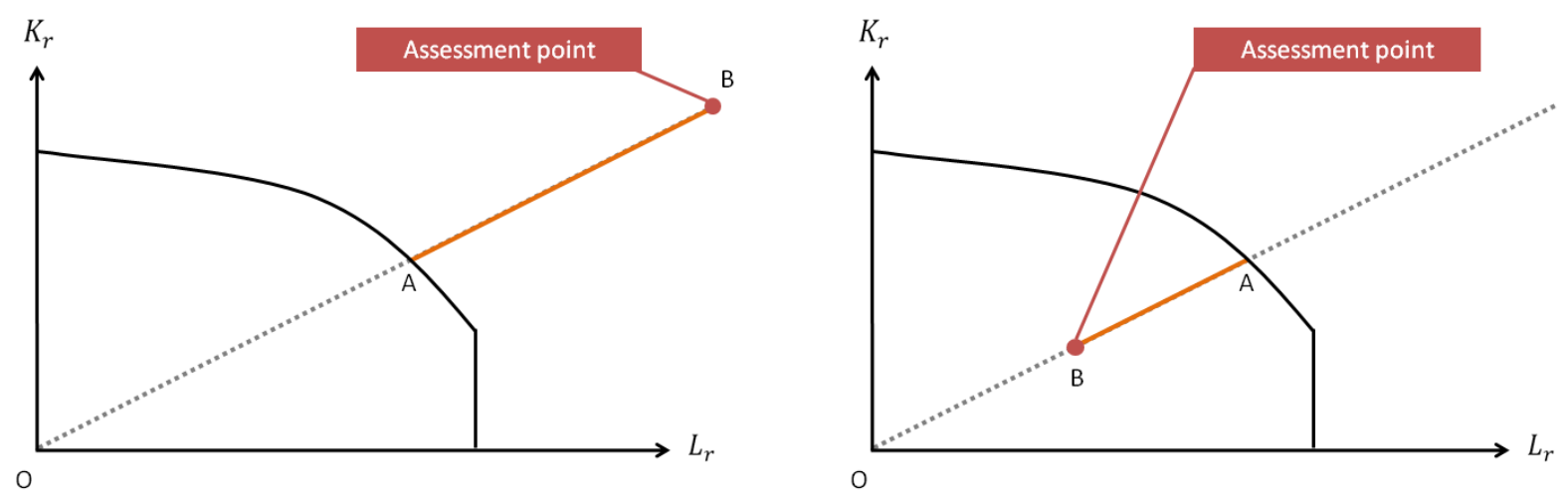

Figure 6. a) Degree of safety of the predicted failures (left) and b) Degree of unsafety of the predicted failures (right) 


\section{COMPARISON \& DISCUSSION}

To judge which of the above reference stress equations predicts failure in the most accurate way, the different FADs have been compared according to different criteria. It should again be mentioned that the fracture ratio has been calculated using the Newman \& Raju equation only.

\subsection{Number of (un)safe predictions}

A first comparison of the different equations is based on the number of unsafe predictions made by each equation (see Figure 7). A prediction is judged unsafe when the assessment point is located under the failure assessment curve because in that case the assessment procedure would have accepted the defect although failure actually occurred.

When it comes to unsafe predictions, the Net Section Yielding equation and the Miller equation show a high number of unsafe predictions. Willing to predict the failure as accurate as possible, this is not preferred. On the other hand, some equations show no unsafe predictions. From this point of view, the use of the Willoughby, Wilkowski \& Eiber and the FITNET plate equation is recommended. The fact that the first two equations do not show any unconservative predictions is in good agreement with the empirical way in which they were derived. Noteworthy is also the high number of invalid predictions in case of the Goodall \& Webster equation, which appear from deep cracks (deeper than half wall thickness).

\subsection{Degree of safety}

Besides the number of safe predictions, it is also useful to compare the degree of safety. When the failure is safely predicted, the degree of safety is defined corresponding Figure 6a as:

$$
\text { degree of safety }=|A B|
$$

The higher this number is, the more conservative the assessment is. From Figure 8 it can be concluded that the FITNET plate reference stress equation should not be recommended although no unconservative predictions were made. The predictions based on this equation incorporate too much conservatism, which does not enable an economical efficient design.

The difference between the other equations is limited, although it can be seen that the Goodall \& Webster equation shows the best performance. The difference between this equation and for instance the Wilkowski \& Eiber equation is still $18 \%$.

\subsection{Degree of unsafety}

On the other hand, in case of an unsafe prediction, the degree of unsafety is also important. A small degree of unsafety might be acceptable because other safety factors are included in the assessment procedure. Analogue to the degree of safety, the degree of unsafety is defined as illustrated in Figure $6 \mathrm{~b}$ :

$$
\text { degree of unsafety }=|A B|
$$

The degree of unsafety is compared for all reference stress equations in Figure 9. Hereby, the reference stress equations, which showed a large number of unsafe predictions or a large degree of safety are marked in grey and the focus is on the equations left. Taking into account the absence of unsafe predictions in some cases, a degree of unsafety equal to zero can be understood. Focusing on the equations which made unsafe predictions, the Sattari-Far equation and the Lei equation show a larger degree of unsafety than the Goodall \& Webster equation. 
Day of Research 2010 - February 10 - Labo Soete, Ghent University, Belgium

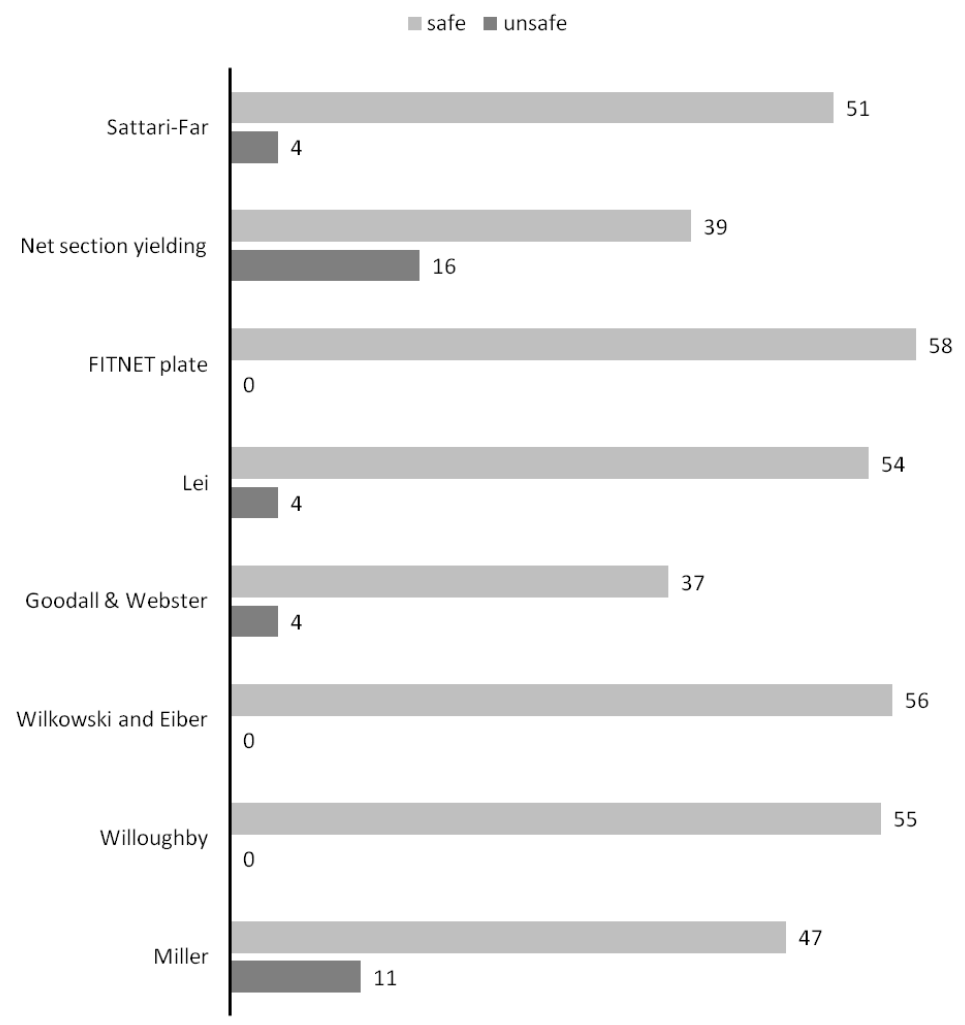

Figure 7. Comparison of the number of (un)safe predictions

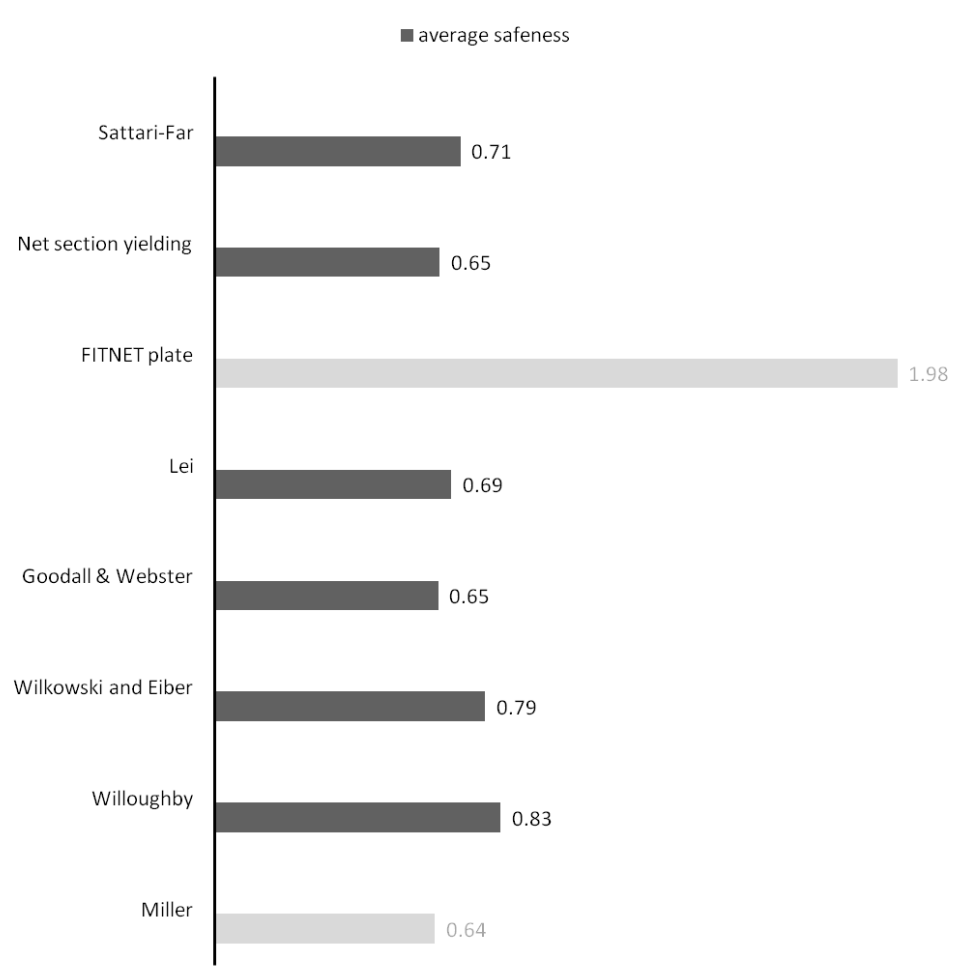

Figure 8. Comparison of the average and maximum safeness 


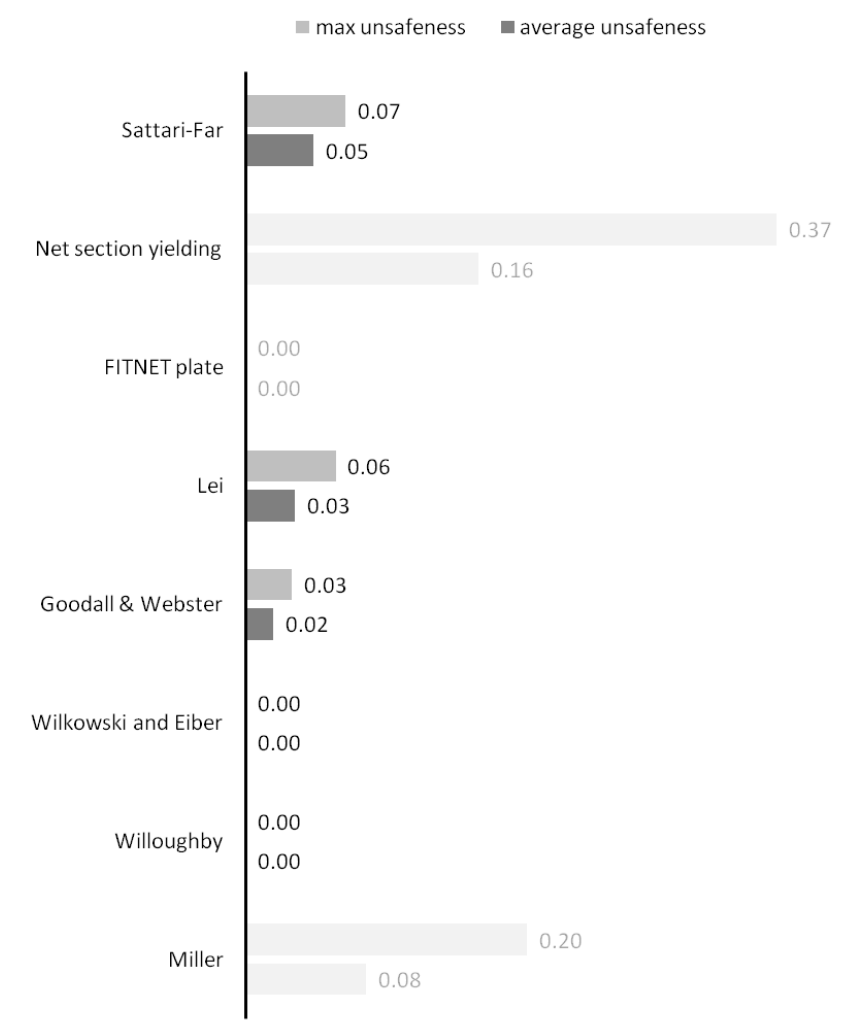

Figure 9. Comparison of the average and maximum unsafeness

\section{CONCLUSIONS}

Tree criteria have been used to compare and evaluate different reference stress equations. The flat plate solution of Newman \& Raju is always used for calculating the fracture ratio. A historical database of full-scale bending experiments on (welded) pipes with circumferential defects has been assessed using the FAD approach. A number of different pipe and plate solutions have been used to calculate the reference stress and load ratio. From this comparison it can be concluded that the use of a flat plate solution, the Goodall \& Webster equation, shows a comparable performance to the full pipe solutions by Wilkowski \& Eiber and Willoughby. The strength of these three equations, compared to the other equations used in this comparison, is the limited degree of safety and unsafety in combination with a small number of unsafe predictions.

The two empirical equations, namely the Wilkowski \& Eiber and the Willoughby equation, have the advantage over the Goodall \& Webster equation that no unsafe predictions were made. On the other hand, the degree of safety is larger $(+18 \%)$ for these empirical equations which might result in a more economical efficient design in case the Goodall \& Webster equation is used. The most restrictive condition for using the Goodall \& Webster equation is the fact that it is only applicable to shallow defects $(a / t<0.5)$.

Therefore, we advise to use the Goodall \& Webster reference stress equation when an engineering critical assessment has to be performed for circumferential defects in pipes subjected to a bending load. If this equation is not valid, when the defect is too deep, the Wilkowski \& Eiber or Willoughby equation should be used. 
Day of Research 2010 - February 10 - Labo Soete, Ghent University, Belgium

\section{NOMENCLATURE}

$\begin{array}{lll}\sigma_{Y S} & \text { Yield stress } & \mathrm{MPa} \\ \sigma_{U T S} & \text { Ultimate tensile stress } & \mathrm{MPa} \\ \sigma_{r e f} & \text { Reference stress } & \mathrm{MPa} \\ L_{r} & \text { Load ratio } & - \\ K_{r} & \text { Fracture ratio } & - \\ K_{\text {mat }} & \text { Charpy V-notch toughness } & \mathrm{MPa} \sqrt{\mathrm{m}} \\ \varepsilon_{f} & \text { Strain at failure } & -\end{array}$

\section{ACKNOWLEDGEMENTS}

The authors would like to acknowledge the support of IWT (Agentschap voor Innovatie door Wetenschap en Techniek - $n^{\circ}$ SB-091512) and the FWO (Fonds Wetenschappelijk Onderzoek - $n^{\circ} 1.1 .880 .09 . \mathrm{N}$ ). 
9 APPENDIX A: EXPERIMENTAL TEST DATA $[5,6]$

\begin{tabular}{|c|c|c|c|c|c|c|c|}
\hline $\begin{array}{c}\mathrm{D} \\
{[\mathrm{mm}]}\end{array}$ & $\begin{array}{c}\mathrm{t} \\
{[\mathrm{mm}]}\end{array}$ & $\left.\begin{array}{c}2 \mathrm{c} \\
{[\mathrm{mm}]}\end{array}\right]$ & $\begin{array}{c}\mathrm{a} \\
{[\mathrm{mm}]}\end{array}$ & $\begin{array}{c}\mathrm{K}_{\text {mat }} \\
{[\mathrm{MPa} \sqrt{ } \mathrm{m}]}\end{array}$ & $\begin{array}{c}\sigma_{\mathrm{YS}} \\
{[\mathrm{Mpa}]}\end{array}$ & $\begin{array}{c}\mathrm{M}_{\text {fail }} \\
{[\mathrm{kNm}]}\end{array}$ & $\begin{array}{c}\varepsilon_{f} \\
{[\%]}\end{array}$ \\
\hline 914 & 11.1 & 63.5 & 5.9 & 136 & 531 & 6704 & 0.5 \\
\hline 914 & 11.1 & 69.8 & 5.5 & 136 & 531 & 6704 & 0.5 \\
\hline 914 & 11.1 & 68.6 & 7.8 & 74 & 531 & 5480 & 0.3 \\
\hline 914 & 11.1 & 61.0 & 5.4 & 74 & 531 & 5286 & 0.3 \\
\hline 914 & 11.1 & 76.5 & 10.1 & 74 & 531 & 2504 & 0.1 \\
\hline 914 & 11.1 & 81.8 & 8.8 & 136 & 531 & 6074 & 0.5 \\
\hline 914 & 11.1 & 59.3 & 6.4 & 74 & 531 & 4358 & 0.2 \\
\hline 914 & 11.1 & 79.0 & 9.3 & 136 & 531 & 6074 & 0.5 \\
\hline 914 & 11.1 & 63.5 & 6.3 & 136 & 531 & 7001 & 0.5 \\
\hline 914 & 11.1 & 59.6 & 6.1 & 136 & 531 & 5675 & 0.4 \\
\hline 914 & 11.1 & 64.8 & 5.5 & 136 & 531 & 6732 & 0.5 \\
\hline 914 & 11.1 & 60.3 & 5.5 & 136 & 531 & 6333 & 0.5 \\
\hline 914 & 10.3 & 300.0 & 4.1 & 154 & 689 & 5926 & 0.8 \\
\hline 914 & 10.3 & 300.0 & 3.6 & 154 & 689 & 5926 & 0.7 \\
\hline 914 & 11.1 & 265.0 & 3.3 & 136 & 531 & 5276 & 0.3 \\
\hline 914 & 11.1 & 278.0 & 3.2 & 136 & 531 & 5888 & 0.4 \\
\hline 914 & 11.1 & 279.0 & 3.9 & 127 & 466 & 3811 & 0.2 \\
\hline 914 & 11.1 & 331.0 & 3.7 & 127 & 466 & 3616 & 0.2 \\
\hline 914 & 11.1 & 75.0 & 3.5 & 127 & 466 & 6074 & 0.5 \\
\hline 1067 & 15.0 & 14.0 & 0.9 & 131 & 496 & 10349 & 0.7 \\
\hline 1067 & 15.0 & 38.0 & 3.0 & 131 & 496 & 10349 & 0.8 \\
\hline 1067 & 15.0 & 70.0 & 8.0 & 131 & 496 & 10349 & 0.6 \\
\hline 914 & 11.1 & 315.0 & 3.7 & 187 & 441 & 4887 & 0.3 \\
\hline 914 & 11.1 & 282.0 & 3.1 & 127 & 466 & 4358 & 0.3 \\
\hline 914 & 11.7 & 280.0 & 2.9 & 128 & 470 & 5219 & 0.4 \\
\hline 914 & 11.7 & 134.0 & 3.7 & 128 & 470 & 4514 & 0.3 \\
\hline 914 & 11.7 & 116.0 & 2.2 & 128 & 470 & 6423 & 0.7 \\
\hline 610 & 6.8 & 100.0 & 3.1 & 121 & 532 & 1225 & 0.2 \\
\hline 610 & 6.8 & 199.0 & 2.8 & 121 & 532 & 1074 & 0.2 \\
\hline 610 & 6.8 & 51.0 & 3.1 & 121 & 532 & 1363 & 0.3 \\
\hline 610 & 6.8 & 107.0 & 3.9 & 120 & 532 & 1290 & 0.2 \\
\hline 508 & 8.7 & 108.0 & 8.7 & 20 & 469 & 1306 & - \\
\hline 508 & 8.7 & 42.6 & 4.8 & 20 & 469 & 1437 & - \\
\hline 508 & 8.7 & 44.9 & 8.7 & 20 & 469 & 1396 & - \\
\hline 508 & 8.7 & 52.4 & 6.4 & 20 & 469 & 1383 & - \\
\hline 508 & 8.7 & 52.4 & 6.8 & 20 & 469 & 1410 & - \\
\hline 508 & 8.7 & 50.0 & 5.9 & 20 & 469 & 1437 & - \\
\hline 762 & 15.8 & 239.0 & 11.9 & 20 & 573 & 4064 & - \\
\hline 762 & 15.8 & 239.0 & 7.9 & 20 & 573 & 4312 & - \\
\hline 762 & 15.8 & 119.0 & 7.9 & 20 & 573 & 5422 & - \\
\hline 762 & 15.8 & 239.0 & 7.9 & 20 & 573 & 4826 & - \\
\hline 914 & 11.7 & 112.0 & 2.0 & 126 & 460 & 6207 & 0.8 \\
\hline 914 & 11.7 & 141.0 & 3.9 & 126 & 460 & 6148 & 0.4 \\
\hline 914 & 11.7 & 300.0 & 3.5 & 126 & 460 & 4516 & 0.3 \\
\hline 762 & 19.0 & 105.0 & 3.5 & 81 & 472 & 6244 & 0.4 \\
\hline 762 & 19.0 & 139.0 & 3.7 & 99 & 472 & 6564 & 0.5 \\
\hline 762 & 19.0 & 125.0 & 5.0 & 121 & 472 & 5737 & 0.5 \\
\hline 711 & 25.4 & 127.0 & 10.9 & 114 & 470 & 7524 & 0.6 \\
\hline 762 & 15.9 & 89.0 & 6.4 & 58 & 487 & 4007 & 0.2 \\
\hline 762 & 15.9 & 597.0 & 3.1 & 58 & 487 & 3231 & 0.2 \\
\hline 762 & 15.9 & 89.0 & 2.5 & 58 & 487 & 5087 & 0.9 \\
\hline 914 & 25.0 & 178.0 & 4.6 & 188 & 486 & 14974 & 1.1 \\
\hline 914 & 25.0 & 199.0 & 5.9 & 93 & 499 & 14056 & 0.6 \\
\hline 914 & 25.0 & 212.0 & 6.1 & 73 & 514 & 8103 & 0.2 \\
\hline 914 & 25.0 & 207.0 & 6.1 & 60 & 526 & 12782 & 0.5 \\
\hline 914 & 25.0 & 191.0 & 12.3 & 188 & 486 & 13178 & 0.6 \\
\hline 914 & 25.0 & 205.0 & 12.0 & 93 & 499 & 12573 & 0.5 \\
\hline 914 & 25.0 & 210.0 & 11.5 & 73 & 514 & 11508 & 0.3 \\
\hline 914 & 25.0 & 210.0 & 15.4 & 60 & 526 & 7310 & 0.2 \\
\hline
\end{tabular}


Day of Research 2010 - February 10 - Labo Soete, Ghent University, Belgium

10 APPENDIX B: NEWMAN AND RAJU EQUATION

With:

$$
K_{I}=\left(S_{t}+H S_{b}\right) \sqrt{\pi \frac{a}{Q}} F
$$

$$
\begin{aligned}
& Q=1+1.464\left(\frac{a}{c}\right)^{1.65} \\
& F=\left[M_{1}+M_{2}\left(\frac{a}{t}\right)^{2}+M_{3}\left(\frac{a}{t}\right)^{4}\right] f_{\phi} g f_{w} \\
& M_{1}=1.13-0.09 \frac{a}{c} \\
& M_{2}=-0.54+\frac{0.89}{0.2+a / c} \\
& M_{3}=0.5-\frac{1.0}{0.65+a / c}+14\left(1.0-\frac{a}{c}\right)^{24} \\
& g=1+\left[0.1+0.35\left(\frac{a}{t}\right)^{2}\right](1-\sin \phi)^{2} \\
& f_{\phi}=\left[\left(\frac{\mathrm{a}}{\mathrm{c}}\right)^{2} \cos ^{2} \phi+\sin ^{2} \phi\right]^{1 / 4} \\
& f_{w}=\left[\sec \frac{\pi c}{2 W} \sqrt{\frac{a}{t}}\right]^{1 / 2} \\
& H=H_{1}+\left(H_{2}-H_{1}\right) \sin ^{\mathrm{p}} \phi \\
& p=0.2+\frac{a}{c}+0.6 \frac{a}{t} \\
& H_{1}=1-0.34 \frac{a}{t}-0.11 \frac{a}{c} \frac{a}{t} \\
& H_{2}=1+G_{1} \frac{a}{t}+G_{2}\left(\frac{a}{t}\right)^{2} \\
& G_{1}=-1.22-0.12 \frac{a}{c} \\
& G_{2}=0.55-1.05\left(\frac{a}{c}\right)^{0.75}+0.47\left(\frac{a}{c}\right)^{1.5}
\end{aligned}
$$


Day of Research 2010 - February 10 - Labo Soete, Ghent University, Belgium

With:

$h \quad$ Half-length of cracked plate $[\mathrm{mm}]$

$M \quad$ Applied bending moment $[\mathrm{Nm}]$

$S_{b} \quad$ Remote bending stress on outer fiber $[\mathrm{Pa}]$

$$
=\frac{3 M}{W t^{2}}
$$

$S_{t} \quad$ Remote uniform tension stress $[\mathrm{Pa}]$

$t \quad$ Plate thickness [mm]

$\phi \quad$ Parametric angle of the ellipse [deg]

Boundary condition:

$$
\begin{aligned}
& 0<\frac{\mathrm{a}}{\mathrm{c}} \leq 1 \\
& 0 \leq \mathrm{a} / \mathrm{t}<1 \\
& c / W<0,5 \\
& 0 \leq \phi \leq \pi
\end{aligned}
$$


Day of Research 2010 - February 10 - Labo Soete, Ghent University, Belgium

\section{REFERENCES}

1. API 1104: Welding of pipelines and related facilities. 2007, American Petroleum Institute.

2. BS 7910: Guide to methods for assessing the acceptability of flaws in metallic structures. 2005, British Standards Institution.

3. FITNET: Fitness-for-Service Procedure. 2006, European Fitness-for-Service network.

4. Newman, J.C. and I.S. Raju, Analyses of surface cracks in finite plates under tension or bending loads. NASA Technical paper 1578, 1979.

5. Pistone, V., Fitness-for-Purpose assessment of defects in pipeline girth welds. EPRG.

6. Coote, R.I., et al., Alternative girth weld acceptance standards in the Canadian gas pipeline code. 1986.

7. Miller, A.G., Review of Limit loads of structures containing defects. Int. J. Pres. Ves. \& Piping, 1988. 32: p. 197-327.

8. Goodall, I.W. and G.A. Webster, Theoritical determination of reference stress for partially penetrating flaws in plates. Int. J. Pres. Ves. \& Piping, 2001. 78: p. 687-695.

9. Lei, Y., J-integral and limit load analysis of semi-elliptical surface cracks in plates under combined tension and bending. Int. J. Pres. Ves. \& Piping, 2004. 81: p. 43-56.

10. Denys, R.M., et al., Effects of stable ductile crack growth on plastic collapse defect assessments. Pipeline technology: Proceedings of the third international pipeline technology conference, 2000. 1: p. 169189.

11. Denys, R.M., et al., Failure characteristics and defect tolerance levels of girth welds in large diameter X65/X70 steel pipelines: experimental verification through wide plate testing and comparison with ECA prediction models. Pipeline technology: Proceedings of the third international pipeline technology conference, 2000. 1: p. 151-167.

12. Sattari-Far, I. and P. Dillström, Local limit load solutions for surface cracks in plates and cylinders using finite element analysis. Int. J. Pres. Ves. \& Piping, 2004. 81: p. 57-66.

13. Zerbst, U., R.A. Ainsworth, and K.H. Schwalbe, Basic principles of analytical flaw assessment methods. Int. J. Pres. Ves. \& Piping, 2000. 77: p. 855-867. 